\title{
Reconsideration of Intrinsic Band Alignments within Anatase and Rutile $\mathrm{TiO}_{2}$ (Viewpoint)
}

By Yoshio Nosaka and Atsuko Y. Nosaka

Department of Materials Science and Technology, Nagaoka University of Technology, Nagaoka 940-2188, Japan

(S1) Interfacial charge transfer for $\mathrm{Cu}(\mathrm{II})$-grafted $\mathrm{TiO}_{2}$ powder

(A)

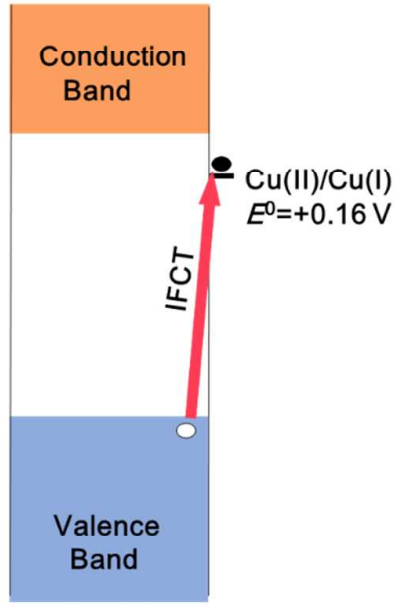

(B)

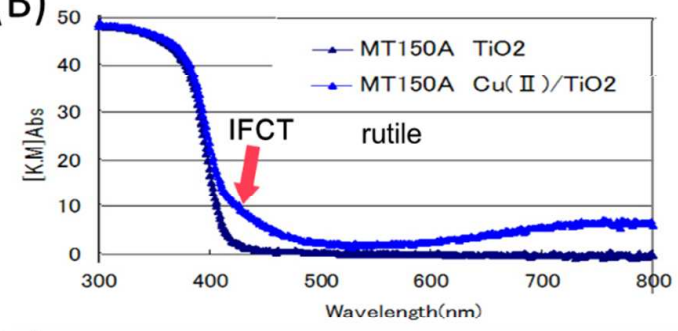

(C)

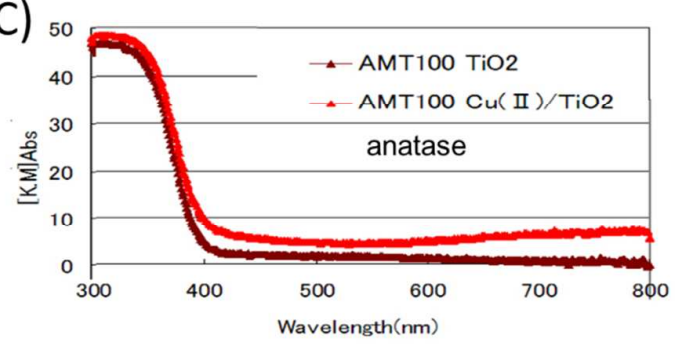

Figure S1. (A) Photo-absorption caused by IFCT (interfacial charge transfer) from valence band to deposited $\mathrm{Cu}$ (II) cluster. (B),(C) Absorption (Kubelka-Munk function) spectra of (B) rutile and (C) anatase $\mathrm{TiO}_{2}$ with and without $\mathrm{Cu}(\mathrm{II})$ deposition.

Irie et al. ${ }^{\mathrm{S} 1}$ showed the photo-excitation of electrons from valence band to $\mathrm{Cu}(\mathrm{II})$ clusters 
deposited on $\mathrm{TiO}_{2}$ powder (Figure $\mathrm{S} 1(\mathrm{~A})$ ) to enhance the photocatalysis induced by visible light. This photo-excitation is called as interfacial charge transfer (IFCT). As shown in Figure S1(B) for rutile $\mathrm{TiO}_{2}$ (MT-150A, TAYCA Inc.), IFCT absorption appeared by the deposition of $\mathrm{Cu}$ (II) clusters at about $450 \mathrm{~nm}$ and the absorbance became larger in the shorter wavelength region. The broad absorption band at 700-800 $\mathrm{nm}$ is attributable to the d-d transition of the deposited $\mathrm{Cu}$ (II). By assuming that the redox potential $E^{0}$ of $\mathrm{Cu}(\mathrm{II}) / \mathrm{Cu}(\mathrm{I})$ is $+0.16 \mathrm{~V}$, the $E_{\mathrm{VB}}$ of rutile is calculated to be $+2.9 \mathrm{~V}$ (SHE) because photons of $450 \mathrm{~nm}$ in the wavelength possess the energy of $2.76 \mathrm{eV}$.

As shown in Figure $\mathrm{S} 1(\mathrm{C})$, for the anatase $\mathrm{TiO}_{2}$ powder (AMT-100, TAYCA Inc.), the IFCT band did not appear by the deposition of $\mathrm{Cu}(\mathrm{II})$. The lack of IFCT absorption around 450 nm suggests that $E_{\mathrm{VB}}$ of anatase should locate at the potential lower than that of rutile. IFCT absorption for anatase is likely overlapped with the inter-band absorption in the wavelength region shorter than $390 \mathrm{~nm}$. In other words, $E_{\mathrm{CB}}$ of anatase is suggested to be below the reduction potential of $\mathrm{Cu}(\mathrm{II})(+0.16 \mathrm{~V})$ in the energy diagram in Figure $\mathrm{S} 1(\mathrm{~A})$. This experimental result is consistent with the band alignment of Figure 1(B).

\section{(S2) Energy-band diagram and DOS reported for rutile and anatase $\mathrm{TiO}_{2}$}
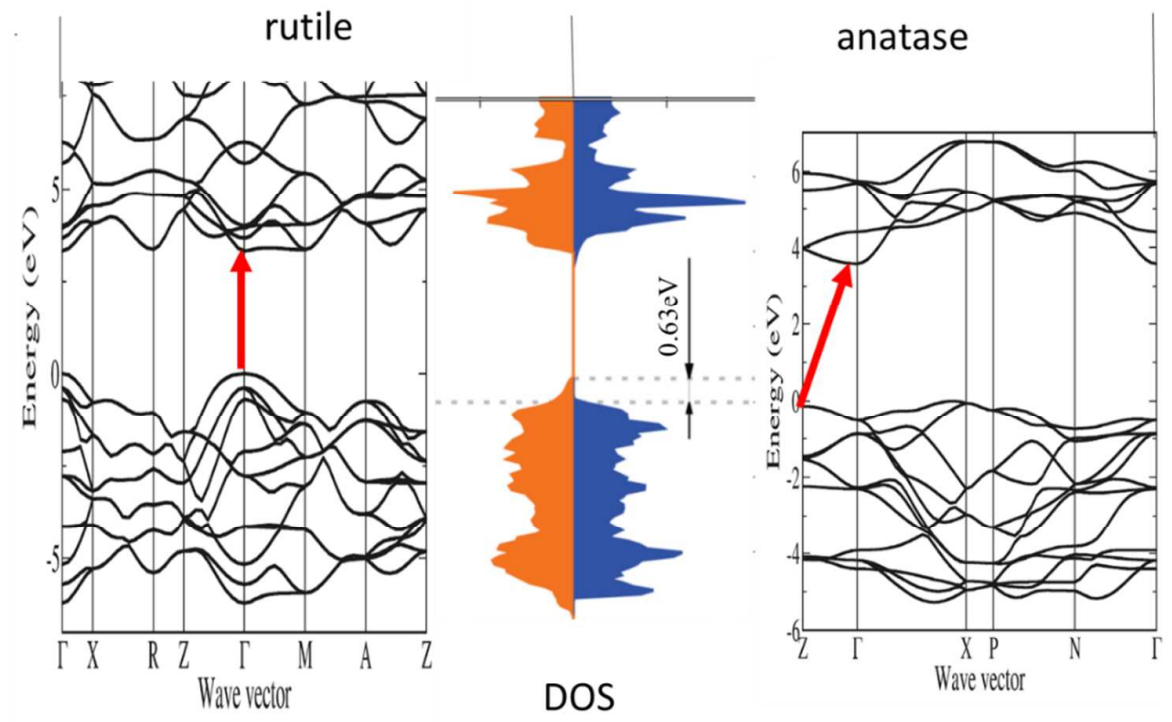

Figure S2. Energy-band diagram ${ }^{\mathrm{S} 2}$ and DOS (density of states) ${ }^{\mathrm{S} 3}$ calculated for rutile and anatase $\mathrm{TiO}_{2}$ with density function theory. Reproduced from Ref. S2 and Ref. S3, respectively.

The energy-band diagrams ${ }^{\mathrm{S} 2}$ for rutile and anatase $\mathrm{TiO}_{2}$ calculated theoretically are shown in both sides of Figure S2. The diagram for rutile shows that the minimum energy for electron excitation is the transition from $\Gamma$ of VB top to $\Gamma$ of $\mathrm{CB}$ bottom, while for anatase that is the 
transition from $\mathrm{Z}$ of VB top to $\Gamma$ of $\mathrm{CB}$ bottom as indicated with each arrow. The density of the states (DOS) near the bottom of CB for anatase becomes small as shown in the middle of Figure S2.

\section{Acknowledgment}

The authors thank Miss Ayano Matsuzaki for preparing $\mathrm{Cu}(\mathrm{II})$-deposited $\mathrm{TiO}_{2}$ powders and measuring the absorption spectra.

\section{References}

(S1) Irie, H.; Kamiya, K.; Shibanuma, T.; Miura, S.; Tryk, D. A.; Yokoyama, T.; Hashimoto, K. Visible Light-Sensitive $\mathrm{Cu}(\mathrm{II})-\mathrm{Grafted} \mathrm{TiO}_{2}$ Photocatalysts: Activities and X-ray Absorption Fine Structure Analyses, J. Phys. Chem. C, 2009, 113, 10761-10766.

(S2) Deák, P.; Aradi, B.; Frauenheim, T. Band Lineup and Charge Carrier Separation in Mixed Rutile-Anatase Systems. J. Phys. Chem. C, 2011, 115, 3443-3446.

(S3) Pfeifer, V.; Erhart, P.; Li, S.; Rachut, K.; Morasch, J.; Brötz, J.; Reckers, P.; Mayer, T.; Rühle, S.; Zaban, A.; Mora Sero, I.; Bisquert, J.; Jaegermann, W.; Klein, Energy Band Alignment between Anatase and Rutile $\mathrm{TiO}_{2}$, J. Phys. Chem. Lett. 2013, 4, 4182-4187. 